\title{
Is Heparan Sulfate in the Glomerular Basement Membrane Necessary for the Etiology of Diabetic Nephropathy?
}

Akiko Saito-Hakoda', Naotaka Kogure1, Takeo Yoshikawa², Kyoko Shimizu1, Yuko Iki', Ikuko Sato', Masataka Kudo ${ }^{1}$, Akira Uruno4, Ken Matsuda $^{3}$, Rehana Parvin'1, Kaori Sugawara1, Atushi Yokoyama1, Sadayoshi Ito ${ }^{3}$ and Akira Sugawara ${ }^{1 *}$

${ }^{1}$ Department of Molecular Endocrinology, Tohoku University Graduate School of Medicine, Sendai, Japan

${ }^{2}$ Department of Pharmacology, Tohoku University Graduate School of Medicine, Sendai, Japan

${ }^{3}$ Division of Nephrology, Endocrinology, and Vascular Medicine, Tohoku University Graduate School of Medicine, Sendai, Japan

${ }^{4}$ Department of Medical Biochemistry, Tohoku University Graduate School of Medicine, Sendai, Japan

Heparan sulphate (HS) is a negatively charged glycosaminoglycan covalently attached to a core protein to form a heparan sulfate proteoglycan (HSPG). HSPG is widely expressed on the cell surfaces as well as in the extracellular matrix, and interacts with variety of proteins to perform many biologically important processes. We recently generated systemic knockout mice of Extl3, which encodes $\mathrm{N}$-acetylglucosamine transferases involved in the HS chain initiation/ elongation, and observed that the mice were embryonic lethal at around 9 days postcoitum [1], indicating the necessity of HS for the embryonic development and survival. We also observed that pancreatic $\beta$-cell specific Extl3 knockout mice demonstrated abnormal islet morphology, impairment of $\beta$-cell proliferation, and impaired glucoseinduced insulin secretion [1], suggesting the involvement of HS in the etiology of diabetes mellitus.

Diabetic nephropathy (DN), a major complication of diabetes mellitus, is the leading cause of end-stage renal disease throughout the world, and the elucidation of its etiology is urgently necessary. In patients with DN, loss of HSPG in glomerular extracellular matrices has been reported [2]. Additionally, both the urinary and plasma levels of heparanase, an endoglycosidase that specifically cleaves HS side chains of HSPG, have been reported to be elevated in type 2 diabetic patients [3]. Moreover, an increased urinary heparanase activity was observed in both type 1 and type 2 diabetic patients with proteinuria [4]. Consistent to these clinical observations, gene disruption of heparanase protected the streptozotocin-induced diabetic mice from DN [5], while overexpression of heparanase resulted in the increase of urinary protein [6]. Therefore, the decrease of the anionic charge barrier due to the loss of HS in the glomerular basement membrane (GBM) may possibly be one of the major causes of albuminuria in $\mathrm{DN}$ [7].

However, several reports have demonstrated controversial observations. Agrin is reported to be the pre-domonant HSPG in the GBM, and is recognized as the main source of the anionic charge barrier [8]. Although podocyte-specific knockout mice of agrin resulted in the significant loss of HS in the GBM, their urinary protein levels were demonstrated to be almost equivalent to those of control mice [9]. Additionally, podocyte-specific knockout mice of Ext1 gene, that encodes the polymerase responsible for HS biosynthesis, did not result in a significant increase of urinary protein comparing with control mice [10]. However, although not significant, the urinary albumin level in Ext1 knockout mice was observed to be much higher than that in control mice [10], suggesting the involvement of GBM HS in the etiology of albuminuria. Additionally, since these experiments using agrin and Ext1 knockout mice were performed in the absence of diabetes, they may possibly be inadequate to examine the etiology of DN. Further studies are needed to elucidate the significance of GBM HS in the etiology and progression of DN.

\section{References}

1. Takahashi I, Noguchi N, Nata K, Yamada S, Kaneiwa T, et al. (2009) Important role of heparan sulfate in postnatal islet growth and insulin secretion. BiochemBiophys Res Commun 383: 113-118.

2. Makino H, Ikeda S, Haramoto T, Ota Z (1992) Heparan sulfate proteoglycans are lost in patients with diabetic nephropathy. Nephron 61: 415-421.

3. Shafat I, Ilan N, Zoabi S, Vlodavsky I, Nakhoul F (2011) Heparanase levels are elevated in the urine and plasma of type 2 diabetes patients and associate with blood glucose levels. PLoS One 6: e17312.

4. Rops AL, van den Hoven MJ, Veldman BA, Salemink S, Vervoort G, et al. (2012) Urinary heparanase activity in patients with type 1 and Type 2 diabetes. Nephrol Dial Transplant 27: 2853-2861.

5. Gil N, Goldberg R, Neuman T, Garsen M, Zcharia E, et al. (2012) Heparanase is essential for the development of diabetic nephropathy in mice. Diabetes 61 : 208-216.

6. Zcharia E, Metzger S, Chajek-Shaul T, Aingorn H, Elkin M, et al. (2004) Transgenic expression of mammalian heparanase uncovers physiological functions of heparan sulfate in tissue morphogenesis, vascularization, and feeding behavior. FASEB 18: 252-263.

7. Kolset SO, Reinholt FP, Jenssen T (2012) Diabetic nephropathy and extracellular matrix. J HistochemCytochem 60: 976-986.

8. Groffen AJ, Ruegg MA, Dijkman $\mathrm{H}$, van de Velden TJ, Buskens CA, et al. (1998) Agrin is a major heparan sulfate proteoglycan in the human glomerular basement membrane. J HistochemCytochem 46: 19-27.

9. Harvey SJ, Jarad G, Cunningham J, Rops AL, van der Vlag J, et al. (2007) Disruption of glomerular basement membrane charge through podocytespecific mutation of agrin does not alter glomerular permselectivity. Am J Pathol 171: 139-152.

10. Chen S, Wassenhove-McCarthy DJ, Yamaguchi Y, Holzman LB, van Kuppevelt $\mathrm{TH}$, et al. (2008) Loss of heparan sulfate glycosaminoglycan assembly in podocytes does not lead to proteinuria. Kidney Int 74: 289-299.

${ }^{*}$ Corresponding author: Dr. Akira Sugawara, Department of Molecula Endocrinology, Tohoku University Graduate School of Medicine, Seiryo-machi, Aoba-ku, Sendai, Japan, Tel: 980-8575; E-mail: akiras2i@med.tohoku.ac.jp

Received January 16, 2014; Accepted January 18, 2014; Published January 24 2014

Citation: Saito-Hakoda A, Kogure N, Yoshikawa T, Shimizu K, Iki Y, et al. (2014) Is Heparan Sulfate in the Glomerular Basement Membrane Necessary for the Etiology of Diabetic Nephropathy? J Biomol Res Ther 3: e127. doi: 10.4172/21677956.1000e127

Copyright: (C) 2014 Saito-Hakoda A, et al. This is an open-access article distributed under the terms of the Creative Commons Attribution License, which permits unrestricted use, distribution, and reproduction in any medium, provided the original author and source are credited. 